\title{
Role of Mitofusin-2 in High Mobility Group Box-1 Protein-Mediated Apoptosis of T Cells in Vitro
}

\author{
Zong-sheng Wu $\mathrm{u}^{\mathrm{a}, \mathrm{c}, \mathrm{d}}$ Yong-ming Yao ${ }^{\mathrm{b}, \mathrm{d}}$ Guang-liang Hong ${ }^{\mathrm{a}}$ Xiu-ping $\mathrm{Xu}^{\mathrm{a}}$ \\ Yao Liu ${ }^{a}$ Ning Dong ${ }^{b}$ Jia-yi Zhenga Zhong-qiu Lu ${ }^{a}$ Guang-ju Zhao ${ }^{a}$ \\ Xiao-mei Zhu ${ }^{b}$ Qing-hong Zhang ${ }^{b}$ Zhi-yong Sheng ${ }^{b}$ \\ aEmergency Center, The First Affiliated Hospital of Wenzhou Medical University, Wenzhou, 'burns \\ Institute, First Hospital Affiliated the Chinese PLA General Hospital, Beijing, 'Affiliated Second Hospital \\ of Southeast University, Nanjing, P. R. China; 'The first two authors contributed equally to this study
}

\section{Key Words}

High mobility group box-1 protein (HMGB1) • Jurkat T cells $•$ Apoptosis $・$ Mitofusin-2(Mfn2) - Calcium

\begin{abstract}
Background: High mobility group box-1 protein (HMGB1), a ubiquitous nuclear protein, which is recognized as a danger-associated molecular pattern (DAMP) triggering activation of the innate immune system. Previous studies have shown that HMGB1 also plays a role in T cell-mediated immunity, but the effect of HMGB1 on apoptosis of T cells and its precise mechanism remain to be determined. Methods: Two kinds of apoptosis assay techniques were used, i.e., Annexin V-FITC conjunction with PI to identify early apoptotic cells, Hoechst 33342 staining for double-stranded DNA to observe nuclear fragmentation or apoptotic body. The activation status of caspase-3, caspase-8, as well as caspase- 9 was examined by colorimetric assay. The dynamic changes in intracellular calcium concentration $\left(\left[\mathrm{Ca}^{2+}\right]_{i}\right)$ was monitored by flow cytometry. Overexpression of Mfn2 was preformed by lentiviral vector transfection. The mRNA and protein levels of Mfn2 were determined by RT-PCR and Western-blotting. Results: Treatment of Jurkat T cells with recombinant human HMGB1 (rhHMGB1) causes a significant dose-dependent increase in percentage of apoptotic cells. When T cells are incubated with HMGB1 they express decreased mitochondria fusion-related protein mitofusin-2 (Mfn2) and activate mitochondrial apoptotic pathway via elevation of $\left[\mathrm{Ca}^{2+}\right]_{\mathrm{i}^{\prime}}$ Bax insertion, and activation of caspase. Furthermore, overexpression of Mfn2 ameliorates the apoptosis of T cells induced by HMGB1. This occurs at least partly through Mfn2 keeps $\mathrm{Ca}^{2+}$ homeostasis in T cells evidenced by monitoring $\left[\mathrm{Ca}^{2+}\right]_{\mathrm{i}}$ dynamics. Conclusion: $\mathrm{HMGB} 1$ can trigger apoptosis of $\mathrm{T}$ lymphocytes through mitochondrial death pathway associated with $\left[\mathrm{Ca}^{2+}\right]_{i}$ elevation. Mfn2 plays a pivotal role in this process, and it might be a novel therapeutic target in T cell apoptosis related disorders.

Copyright (C) 2014 S. Karger AG, Basel

Zhong-qiu Lu


Wu et al.: Mfn-2 in HMGB1-Mediated Apoptosis of T Cells

\section{Introduction}

In spite of improvements in basic science and clinical medicine, the complex immune dysregulation associated with sepsis results in a high rate of morbidity as well as mortality. Numerous studies in both animals and patients have disclosed a profound apoptosis of peripheral and splenic T lymphocytes during sepsis [1-4]. It is well known that activated $\mathrm{T}$ cells play an irreplaceable role in adaptive immune response through secreting different cytokines and modulating costimulatory molecule expression on the cell surface. Loss of $\mathrm{T}$ cells directly impairs the adaptive immune response and indirectly induces immune tolerance of macrophages and dendritic cells (DCs) which engulf these apoptotic cells, rendering the septic host susceptible to secondary or opportunistic infections [5, 6]. Moreover, it has been shown that mitigation of $\mathrm{T}$ cell apoptosis dramatically reverses immune dysfunction and improves survival in severe sepsis [7].

Although apoptosis of T lymphocytes is a common feature in sepsis, the precise death inducing stimuli and other critical elements still need further clarity. High-mobility group box-1 protein (HMGB1), a nuclear DNA-binding protein secreted by immune cells, such as monocytes, macrophages, and DCs, is recognized as one of pro-inflammatory mediators in sepsis [8]. It was reported that plasma level of HMGB1 was elevated in patients with severe sepsis, and it was correlated with organ dysfunction and patient's outcome [9]. Extracellular HMGB1 is regarded as a danger signal to activate the innate immune system, but also have profound effects on behaviour of immunocompetent cells in adaptive immunity. Accumulating evidences demonstrate that exogenous HMGB1 exerts a potent immunoregulatory effect on a variety of immune cells, as it promotes the expressions of costimulatory molecules and cytokines in DCs [10], the most potent antigen-presenting cell (APC), and regulates migratory responses of macrophages and neutrophils [11], and in particular it induces apoptosis of macrophages in vitro [12]. In addition, our recent study indicated that HMGB1 had a dual regulatory effect on immune function of $\mathrm{T}$ cells varying with different concentrations and stimulation time [13]. Nevertheless, the significance of HMGB1 in inducing T-cell apoptosis and its potential mechanism remained unclear.

The early events in apoptosis are now generally known to occur in mitochondria and the endoplasmic reticulum (ER), where $\mathrm{Ca}^{2+}$ signals are regulated and cell fate is determined. To $\mathrm{T}$ lymphocytes, the increase in intracellular $\mathrm{Ca}^{2+}\left(\left[\mathrm{Ca}^{2+}\right]_{\mathrm{i}}\right)$ by store-operated $\mathrm{Ca}^{2+}$ entry $(\mathrm{SOCE})$ is mainly dependent on $\mathrm{Ca}^{2+}$ release-activated $\mathrm{Ca}^{2+}$ (CRAC) channels [14]. Mitochondria fusionrelated protein mitofusin-2 (Mfn2), a member of mitochondrial dynamin-related GTPases, is reported to be present both in mitochondria and ER, and it regulates mitochondrial uptake of $\mathrm{Ca}^{2+}$ released by the ER [15]. More recently, Mfn2 was found to be involved in regulating migration of stromal interaction molecule 1 (STIM1), which a protein essential for CRAC channel activation [16]. Therefore, we hypothesized that Mfn2 could regulate the progression of T-cell apoptosis through $\mathrm{Ca}^{2+}$ signals. In present study, we attempt to identify the apoptotic effect of HMGB1 on T cells in vitro, and to investigate the potential role of Mfn2 during this process. We showed that treatment with HMGB1 markedly promoted Bcl-2 degradation and Bax accumulation in the mitochondria, and also elevated intracellular $\mathrm{Ca}^{2+}$ levels with collapse of mitochondrial membrane potential, ultimately leading to apoptosis. Overexpression of Mfn-2 in Jurkat $\mathrm{T}$ cells maintained $\mathrm{Ca}^{2+}$ homeostasis and conferred resistance to HMGB1-induced apoptosis. These findings expand the understanding of HMGB1 induced immune dysfunction in sepsis and reveal a role for Mfn2 in disturbance of $\mathrm{Ca}^{2+}$ homeostasis $\mathrm{T}$ cell apoptosis, which might constitute a novel approach to therapeutic intervention for $\mathrm{T}$ cell apoptosis related diseases.

\section{Materials and Methods}

\section{Media and reagents}

RPMI 1640, fetal bovine serum (FBS), glutamine, penicillin, streptomycin, and HEPES were purchased from Gibco, CA. PMA, ionomycin and a cell mitochondrial isolation kit were purchased from the Beyotime 
Wu et al.: Mfn-2 in HMGB1-Mediated Apoptosis of T Cells

Institute, Nanjing, China. The FITC Annexin V Apoptosis Detection Kit I (annexin-V-FITC and PI) was purchased from BD/PharMingen, San Diego, CA. Hoechst 33342 was purchased from Sigma, St. Louis, MO. Recombinant human HMGB1 and caspase detection kits (caspase-3, 8, 9) were purchased from R\&D Systems, Minneapolis, MN. Fluo-3/AM, pluronic F-127 and a JC-1 Assay Kit for Mitochondrial Membrane Potential (MMP) detection were obtained for Molecular Probes, Eugene, OR. Total RNA isolation system and reverse transcription system were purchased from Promega, Madison, WI. SYBR Green PCR Master Mix was purchased from Applied Biosystems, Foster City, CA. Nondenaturing lysis buffer and protease inhibitor cocktail were purchased from Applygen Technologies Inc., Beijing, China. Anti-Bcl-2 antibody, anti-Bax antibody, anti- Mfn-2 antibody, anti-ORAI1 antibody, anti-STIM1, anti- $\beta$-actin antibody and Cox-IV antibody were from Santa Cruz Biotechnology Inc., CA. Amersham ECL ${ }^{\mathrm{TM}}$ advance Western blotting detection kit was purchased from Amersham Pharmacia Biotech, Uppsala, Sweden.

\section{Cell culture and treatment}

Jurkat human T cell line was obtained from Cell Resource Center of Shanghai Institutes of Biological Sciences (Shanghai, China) and was maintained at $37^{\circ} \mathrm{C}$ in a humidified atmosphere of $5 \% \mathrm{CO}_{2}$ in RPMI 1640 supplemented with penicillin/streptomycin $(100 \mathrm{IU} / \mathrm{ml}$ and $100 \mu \mathrm{g} / \mathrm{ml}$, respectively) and $10 \%$ fetal bovine serum. Before each experiment, the cell viability was measured by Trypan blue exclusion.

T cells $\left(1 \times 10^{6} / \mathrm{ml}\right)$ were unstimulated or stimulated with PMA $(50 \mathrm{ng} / \mathrm{ml}) /$ ionomycin $(1 \mu \mathrm{M})[\mathrm{P} / \mathrm{I}]$, and then incubated with recombinant HMGB1 at different concentrations $(0,20,100,500 \mathrm{ng} / \mathrm{ml})$ or PBS, and cells were cultured for 0,24 or 48 hours, respectively. After culture and stimulation as indicated above, cells were collected for Western blot analysis, reverse transcription polymerase chain reaction (RT-PCR) and flow cytometric analysis.

\section{Lentivirus generation and transfection}

A full-length human Mfn2 cDNA was obtained from Genscrip Corporation (Piscataway, NJ). Lentivirus vectors expressing the DNA fragments encoding full-length Mfn2 (LV-Mfn2) was synthesized and provided by GeneChem Co. Ltd., Shanghai, China. As a control, a lentiviral vector that enveloping pGC-FU alone (LVpGC-FU) was also generated. Transfection was performed according to the manufacturer's instruction in Lentiviral Vector Particle. Jurkat T cells $\left(1 \times 10^{6} / \mathrm{ml}\right)$ were plated in cell culture flask $\left(25 \mathrm{~cm}^{2}\right)$ and cultured for $12 \mathrm{~h}$. Then, lentivirus was diluted into final concentrations of $5 \times 10^{7} \mathrm{TU} / \mathrm{ml}$ with culture medium which also contain $5 \mu \mathrm{g} / \mathrm{ml}$ polybrene to enhance transfection effciency. After co-culture with lentivirus $12 \mathrm{~h}, 2.5 \mathrm{ml}$ fresh RPMI 1640(10\% FBS) was added. Transfection effciency of lentiviral vector in Jurkat T cells was monitored by Western blot for Mfn2 three days after transfection. The results were showed in Fig.5 at multiplicity of infection $(\mathrm{MOI})=50$.

For the another part of experiments, T cells $\left(1 \times 10^{6} / \mathrm{ml}\right)$ were infected with LV-Mfn2 or LV-pGC-FU will incubated with PMA (50 ng/ml)/ionomycin $(1 \mu \mathrm{M})$ for 6 hours, and then incubated with recombinant HMGB1(500ng/ml,24h), after that, cells were collected for Western blot analysis and flow cytometric analysis.

\section{Flow cytometric analysis}

Flow cytometry was carried out using a FACScan flow cytometer (BD Biosciences, Mountain View, CA) equipped with a $15 \mathrm{~mW} 488 \mathrm{~nm}$ argon ion laser. Approximately 10000 cells were analyzed from each treatment. Data acquisition was performed using CellQuest software.

Annexin V-FITC and PI staining: Apoptotic cells were identified and quantified using the Annexin V-FITC kit according to instructions of the manufacturer.In briefly, cells were stained with Annexin V (green, to identify apoptosis at an early stage) and PI (red, to identify late apoptosis or already dead). Jurkat T cells $\left(1 \times 10^{5} / \mathrm{ml}\right)$ were collected and washed twice with cold PBS, and then resuspended in $100 \mu$ l binding buffer, to which were added $5 \mu \mathrm{l}$ Annexin V-FITC and $5 \mu \mathrm{l} \mathrm{PI}$. After incubation for 15 minutes in darkness at room temperature (RT), the cells were diluted with $400 \mu \mathrm{l}$ binding buffer and analyzed by flow cytometry within 1 hour using a FACScan.

Mitochondrial membrane potential assay: Mitochondrial membrane potential was measured by flow cytometry using the lipophilic cation 5',6,6'-Tetrachloro-1,1',3,3'-tetraethylbenzimidazolylcarbocyanine iodide (JC-1). Following treatment with rhHMGB1, cells were stained with $20 \mu \mathrm{M} \mathrm{JC}-1$ for 30 minutes at $37^{\circ} \mathrm{C}$. Fluorescence was monitored with the fluorescence plate reader at wave lengths of $490 \mathrm{~nm}$ (excitation)/540 
Wu et al.: Mfn-2 in HMGB1-Mediated Apoptosis of T Cells

Table 1. The nucleotide sequences of the primers used for PCR amplification

\begin{tabular}{lll}
\hline Target gene & \multicolumn{2}{l}{ Oligonucleotide primers $\left(5^{\prime}-3^{\prime}\right)$} \\
\hline Mfn2 & Forward & TGGCTCAAGACTATAAGCTGCG \\
& Reverse & GAGGACTACTGGAGAAGGGTGG \\
\multirow{2}{*}{ GAPDH } & Forward & AGAAGGCTGGGGCTCATTTG \\
& Reverse & AGGGGCCATC CACAGTCTTC \\
\hline
\end{tabular}

$\mathrm{nm}$ (emission) and $540 \mathrm{~nm}$ (excitation)/590nm (emission) pairs. Changes in the ratio of fluorescence intensities between the measurement at test wave lengths of $590 \mathrm{~nm}$ (red) and $540 \mathrm{~nm}$ (green) are indicative of changes in the mitochondrial membrane potential. Carbonyl cyanide 3-chlorophenylhydrazone(CCCP, a mitochondrial membrane potential disrupter) controls were used to confirm that the JC-1 response is sensitive to changes in membrane potential.

Intracellular calcium measurement: To investigate whether $\mathrm{Ca}^{2+}$ signaling was involved in cell apoptosis, we measured the intracellular calcium dynamics in Jurkat $\mathrm{T}$ cells with flow cytometry using the $\mathrm{Ca}^{2+}$-sensitive fluorescent dye Fluo-3/AM. Following exposure, cells were washed twice with HBSS, and $5 \mu \mathrm{M}$ of Fluo-3/AM was loaded for 30 minutes at $37^{\circ} \mathrm{C}$ in the presence of $0.06 \%$ pluronic F-127. Cells were diluted five times in phenol red-free RPMI 1640 that contained $1 \% \mathrm{FBS}$, and they were incubated for another 30 minutes at $37^{\circ} \mathrm{C}$. They were then trypsinized, and washed three times with HEPES buffer saline. The intracellular calcium was analyzed immediately for Fluo-3/AM fluorescence intensity by flow cytometry (excitation at $488 \mathrm{~nm}$ and emission at $525 \mathrm{~nm}$ ).

\section{SYBR green real-time RT-PCR}

After cells were treated as indicated, total RNA was extracted from cells using the single-step technique of acid guanidinium thiocyanate-chloroform extraction according to the manufacturer's instruction (Promega, Madison, WI). The concentration of purified total RNA was determined spectrophotometrically at $260 \mathrm{~nm}$. mRNA expressions of Mfn2 were quantified in duplicate by SYBR green two-step, real-time RTPCR. As an internal control, PCR of GAPDH was performed under the same condition using primers. PCR reaction mixture was prepared using SYBR Green PCR Master Mix with the primers as shown in Table 1. Thermal cycling conditions were 10 minutes at $95^{\circ} \mathrm{C}$ followed by 40 cycles of $95^{\circ} \mathrm{C}$ for 15 seconds and $60^{\circ} \mathrm{C}$ for 1 minute on an Sequence Detection System. Mfn2 gene expression was normalized with GAPDH mRNA content.

Preparation of the whole cell lysate, cytoplasmic and mitochondrial fractions

Cells were collected and washed with cold PBS, and lysed in a density of $10^{6}$ cells $/ 50 \mu$ l of lysis buffer ( $150 \mathrm{mM} \mathrm{NaCl}, 1.0 \% \mathrm{NP}-40$ or $0.1 \%$ Triton X-100, $0.5 \%$ sodium deoxycholate, $0.1 \%$ SDS, $50 \mathrm{mM}$ Tris- $\mathrm{HCl} \mathrm{pH}$ 8.0, protease inhibitors). After incubation on ice for 30 minutes, the homogenate was centrifuged at 12000 $\mathrm{rpm}$ for 25 minutes at $4^{\circ} \mathrm{C}$ and whole cell protein content in the supernatant. Cytoplasm and mitochondria proteins were collected using a cell mitochondrial kit from Beyotime (Beijing, China) in accordance with the manufacturer's instructions. Briefly, after treatment with rhHMGB1 $(500 \mathrm{ng} / \mathrm{ml})$ for 24 hours, $6 \times 10^{7}$ cells were harvested and washed twice with ice-cold PBS. They were then incubated in cell lysis buffer (250 mM sucrose; $1 \mathrm{mM}$ DTT; $10 \mathrm{mM} \mathrm{KCl;} 1 \mathrm{mM}$ EDTA; 1 mM EGTA; $1.5 \mathrm{mM} \mathrm{MgCl}$; phenylmethylsulfonyl fluoride; $20 \mathrm{mM}$ HEPES, $\mathrm{pH} 7.4$ ) at $4^{\circ} \mathrm{C}$. The cell lysate was centrifuged at $800 \times \mathrm{g}$ for 10 minutes to remove any unbroken cells, and the supernatant was further centrifuged at $15000 \times \mathrm{g}$ for 10 minutes at $4^{\circ} \mathrm{C}$. The resulting supernatant contained the cytoplasmic fraction and the pellet contained the mitochondrial fraction. Mitochondrial pellet was further resuspended in a mitochondrial lysis buffer at $4^{\circ} \mathrm{C}$, and both the resuspended mitochondrial pellet and the supernatant were further centrifuged at $24000 \times \mathrm{g}$ at $4^{\circ} \mathrm{C}$ to remove the nuclei. The protein concentration of the whole cell lysate, cytoplasm and mitochondria was measured by the Bradford method using BSA as a standard.

\section{Western blotting analysis}

Cell lysis, SDS-PAGE separation, transfer to nitrocellulose membranes, and development of blots using an Amersham ECL ${ }^{\mathrm{TM}}$ advance Western blotting detection kit were performed as described previously. 
Membranes were probed with following monoclonal antibodies (mAbs) and polyclonal antibodies (pAbs): anti-Mfn2(H-68,sc-50331) pAb,ORAI1(H-46,sc-68895) pAb, STIM1(CDN3H4,sc-66173) mAb, Bax(6D150,sc-70408) mAb, and Bcl-2(C-2,sc-7382) mAb. $\beta$-actin(H-196,sc-7210) pAb and Cox-IV(G20,sc-69360) pAb were used as controls for protein loading. Each protein level was quantified by densitometry using NIH image software.

\section{Hoechst 33342 staining}

After being treated as mentioned above, changes in apoptotic Jurkat $\mathrm{T}$ cells were determined by nuclear staining with the chromatin dye Hoechst 33342. Briefly, cells were fixed for 1 hour in $4 \%$ paraformaldehyde at room temperature, and then exposed to $5 \mu \mathrm{g} / \mathrm{ml}$ Hoechst 33342 for 30 minutes at $37^{\circ} \mathrm{C}$ in darkness. Cells were observed under a fluorescence microscope. Representative fields were photographed for each experiment.

Measurement of caspase activity

Caspase activity (caspase- $3,-8$, and -9) was measured using three caspase assay kits from R\&D Systems. Cells were lysed according to the manufacturer's instructions, and protein concentration was quantified using the Bradford method. Cell lysates (from $10^{6} \mathrm{cells}$ ) were incubated with $5 \mathrm{mM}$ dithiothreitol, and the caspase-3, -8 , and -9 colorimetric substrates were conjugated to color reporter molecule p-nitroanilide (DEVD-pNA, IETD-pNA, LEHD-pNA) in reaction buffer for 2 hours at $37^{\circ} \mathrm{C}$. Cleavage of substrate was quantified using a microplate reader to determine absorbance at $405 \mathrm{~nm}$.

\section{Statistical analysis}

Data were represented as mean \pm standard deviation (SD), and analyzed with one-way ANOVA. Fisher's least significant difference (LSD-t) was used to evaluate significant differences between groups. $\mathrm{P}<0.05$ was considered statistically significant.

\section{Results}

HMGB1-induced apoptosis of Jurkat T cells

To investigate the effect of HMGB1 on T-lymphocyte apoptosis, Jurkat T cells were treated with different concentrations of HMGB1 for different duration after being unstimulated or stimulated with P/I. Two kinds of apoptosis assay techniques were used, i.e., Annexin V-FITC conjunction with PI to identify early apoptotic cells, Hoechst 33342 staining for doublestranded DNA to observe nuclear fragmentation or apoptotic body. As shown in Fig. 1A and 1B, treatment with $100 \mathrm{ng} / \mathrm{ml} \mathrm{HMGB} 1$ for 24 hours or 48 hours significantly induced apoptosis of Jurkat $\mathrm{T}$ cells $(\mathrm{P}<0.01)$, and with increasing concentrations of HMGB1, the percentage of apoptotic cells was also markedly increased in timepoint 24hours $(\mathrm{P}<0.01)$. In line with observation above, the fluorescent microscopic images showed that the longer incubation period and higher concentration of HMGB1, the more cells were found to be accompanied with apoptotic body (Fig. 1C). However, no significant difference in $\mathrm{T}$ lymphocytes was observed between P/I stimulation only group and low-dose HMGB1 (20 ng/ml) group. In addition, marked necrosis or late apoptosis could be noted in activated $\mathrm{T}$ cells exposed to $500 \mathrm{ng} / \mathrm{ml} \mathrm{HMGB1}$ for 48 hours.

\section{HMGB1 activated T cell mitochondrial apoptosis pathway}

In order to discriminate which apoptotic pathway was responsible for HMGB1-induced apoptosis, we examined the activation status of caspase-3, caspase-8, as well as caspase- 9 in response to $500 \mathrm{ng} / \mathrm{ml} \mathrm{HMGB1}$ stimulation for 24 hours. On the one hand, P/I elicited significant caspase-8 activation $(\mathrm{P}<0.05)$ compared with normal. On the other hand, activities of all these caspases were elevated significantly after being exposed to HMGB1 compared with control group in the same cell, such as normal cell, LV-pGC-FU transfected cell( $\mathrm{P}<0.01$, Fig. 2). Caspase-9 (1.9-fold) was shown to be more active than caspase-8 (1.3-fold) following HMGB1 stimulation. 
Fig. 1. Apoptosis of Jurkat $\mathrm{T}$ cells induced by HMGB1. Jurkat $\mathrm{T}$ cells stimulated by PMA (50 $\mathrm{ng} / \mathrm{ml}$ )/io nomycin (1 $\mu \mathrm{M})$ for 6 hours, were treated with $\mathrm{d}$ ifferent d o s a g e $s$ of HMGB1 (20, 100, and $500 \mathrm{ng} /$ $\mathrm{ml}$ ) or without HMGB1 (control). (A, B) After trea tment with HMGB1 for 24 hours or 48 hours, apoptosis of Jurkat T cells were stained with Annexin V-FITC and PI. Representative flow cytometry results from four fields of cells were shown in each experiment. Results

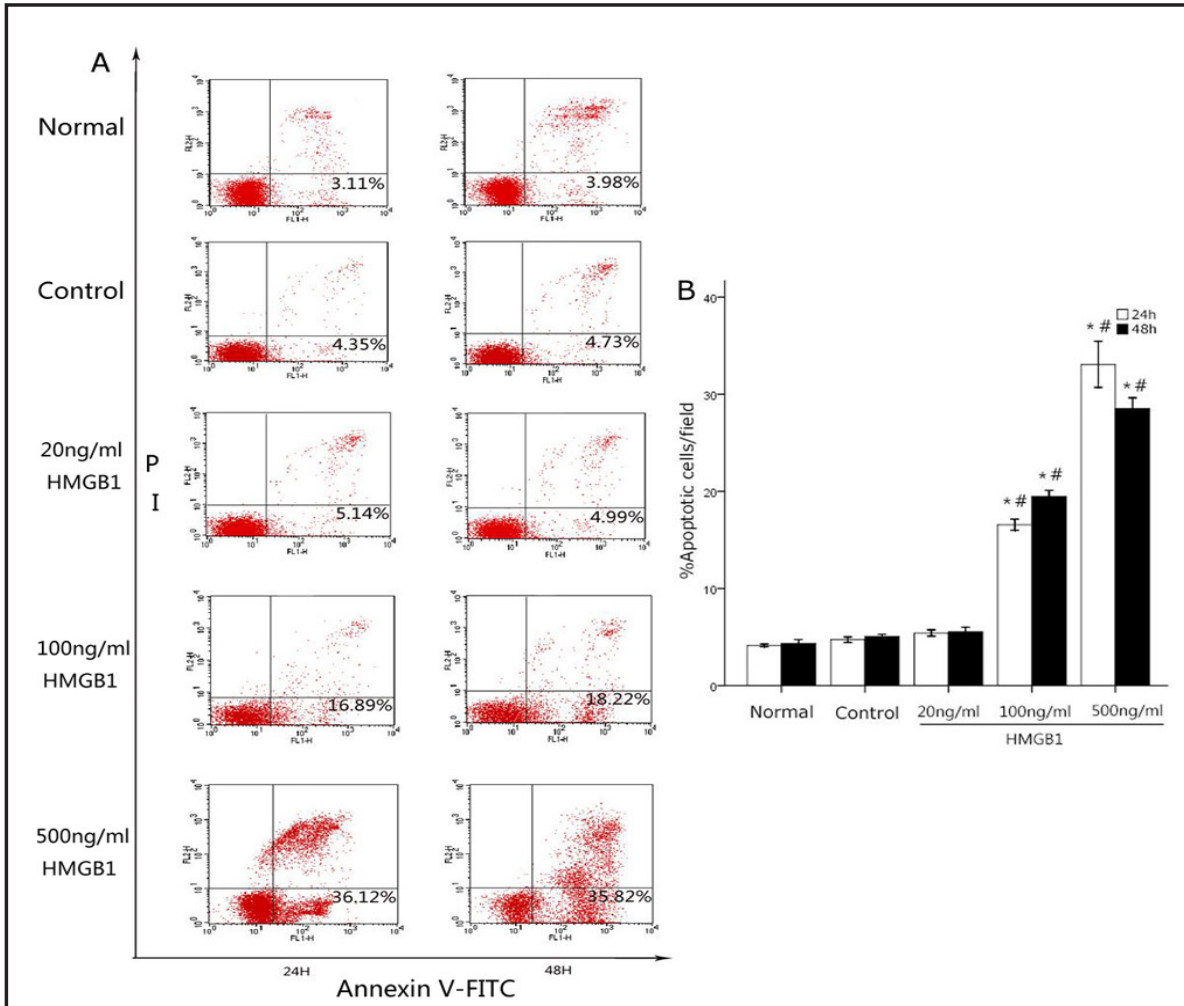

C

Control
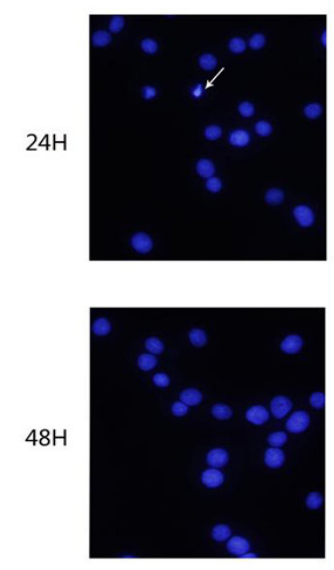

HMGB1 $(\mathrm{ng} / \mathrm{ml})$
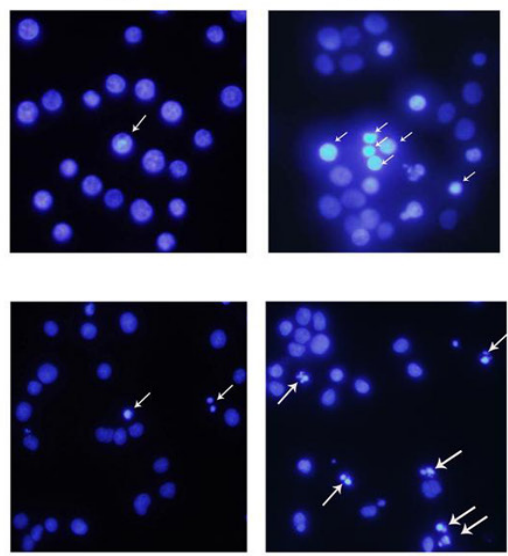

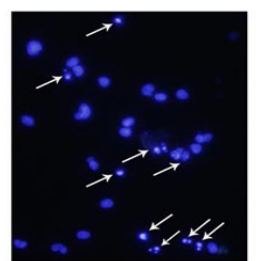

six independent experiments were shown as mean \pm SD. *Statistically significant difference when compared with the normal cells $(\mathrm{P}<0.01)$; \#Statistically significant difference when compared with the controls $(\mathrm{P}<0.01)$. (C) Morphological evaluation of apoptosis in Jurkat T cells. At the end of HMGB1 (20, 100, and 500 $\mathrm{ng} / \mathrm{ml}$ ) incubation period, cells were stained with H-33342 and examined with a fluorescence microscope. The arrow points an apoptotic body in these images. Results were shown as one representative image of six different visual fields. Original magnification $\times 200$.

To further verify the signaling events involved in HMGB1-induced apoptosis, we investigated the potential role of HMGB1 in regulating mitochondrial Bcl-2 family members. Notably, a mitochondrial protein abundance of Bcl-2, which was an antiapoptotic member, was decreased. In contrast, Bax, a proapoptotic member of the family, was translocated from the cytoplasm to the mitochondrial membrane (Fig. 3). Thus, HMGB1 promoted apoptosis of $\mathrm{T}$ cells by activation of caspase- 9 and caspase- 3 , rather than caspase- 8 , and they greatly 


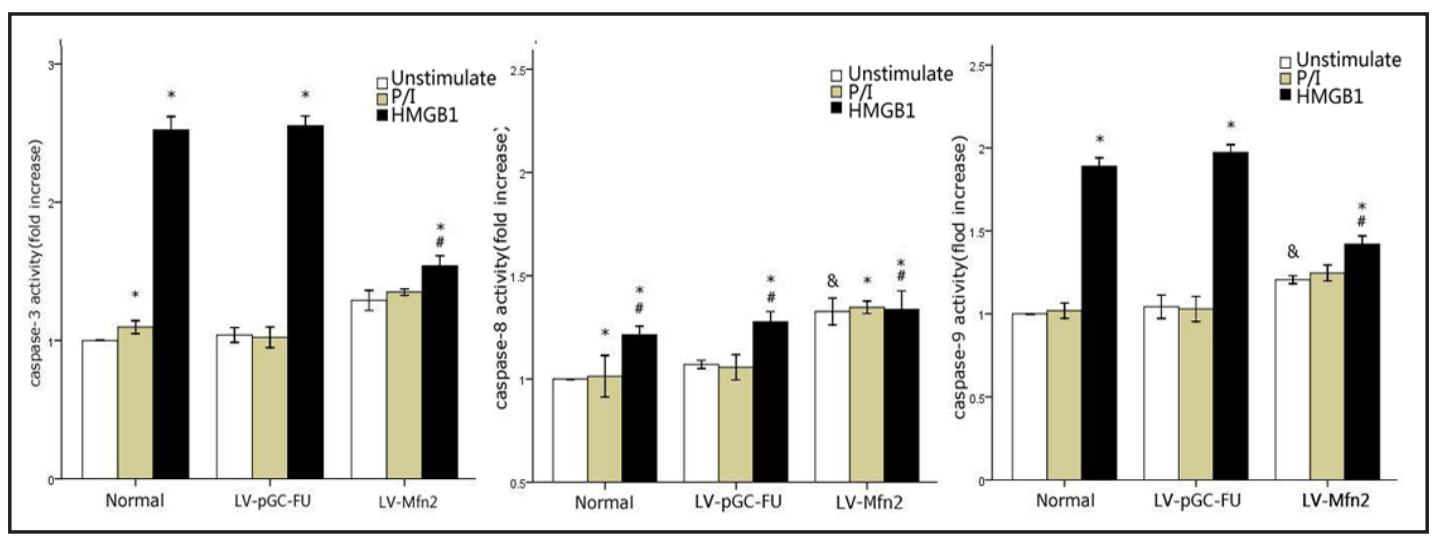

Fig. 2. Caspase-3, -8, and -9 activities in Jurkat T cells with LV-Mfn2 or LV-pGC-FU transfected exposed to $500 \mathrm{ng} / \mathrm{ml} \mathrm{HMGB1}$ (control, P/I) for 24 hours. The values were represented as the mean \pm SD of three replicates. *Statistically significant difference when compared with the unstimulated cells $(\mathrm{P}<0.05)$, \#Statistically significant when compared with the CORRESPONDING LV-pGC-FU cells $(\mathrm{P}<0.01)$; \&Statistically significant difference when compared with normal cells $(\mathrm{P}<0.01)$.

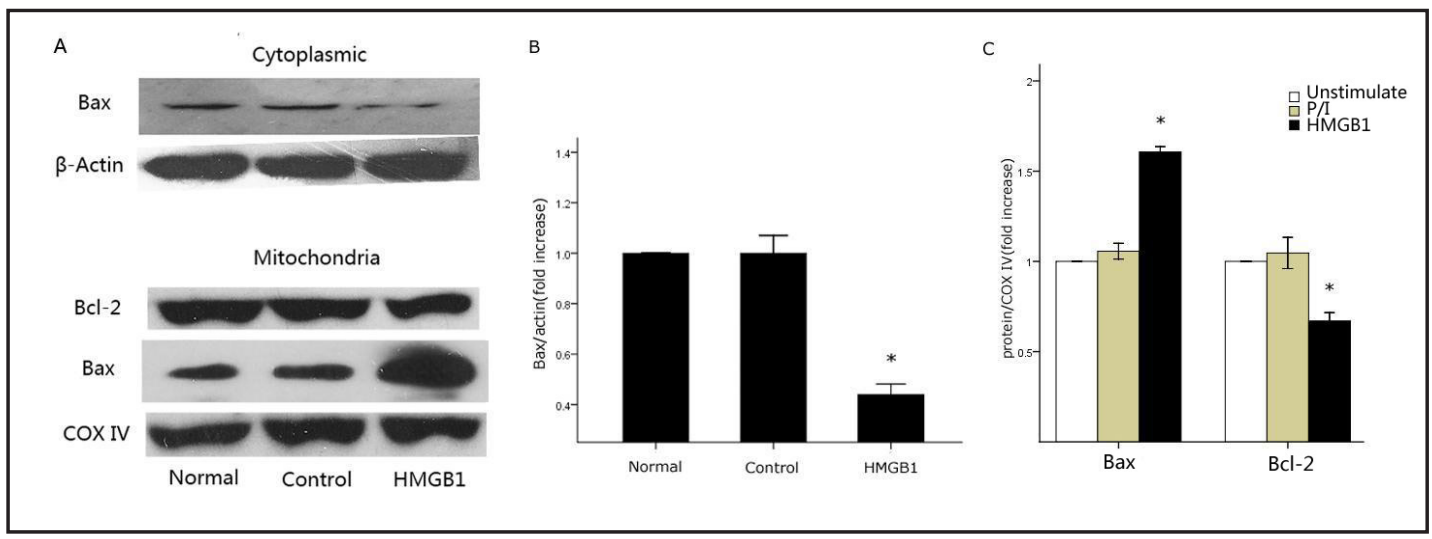

Fig. 3. HMGB1-induced Bax insertion and Bcl-2 decrease in mitochondria of Jurkat T cells. (A)After HMGB1 stimulation (500 ng/ml) as indicated, cytoplasma and mitochondrial fractions were analyzed for the presence of Bax and Bcl-2 using Western blotting. (B and C) Results of gray intensity in interest band. $\beta$-actin and Cox IV were used as loading controls for the cytoplasmic and mitochondrial proteins, respectively. Results of three independent experiments were shown as the mean \pm SD. *Statistically significant difference when compared with the control $(\mathrm{P}<0.05)$.

enhanced the mitochondrial Bax/Bcl-2 ratio, suggesting that HMGB1-induced apoptosis of T cells was more likely mediated by the mitochondrial death pathway.

\section{Mfn2 was involved in apoptosis of T cells induced by HMGB1}

Our previous study have demonstrated that Mfn2 expression was markedly suppressed in T lymphocytes from mice by treatment with HMGB1. To determine if Mfn2 decline is responsible for the proapoptotic effect of HMGB1 on human T cell line, mRNA and protein levels of Mfn2 after HMGB1 stimulation were determined. Upon T cell activation, Mfn2 gene expression was enhanced $(\mathrm{P}<0.01)$. HMGB1 stimulation reduced $\mathrm{Mfn} 2$ gene expression in a dose-dependent fashion with a slight increase in $20 \mathrm{ng} / \mathrm{ml}$, resulting in about $50 \%$ inhibition after treatment of $500 \mathrm{ng} / \mathrm{ml} \mathrm{HMGB1}$ for 24 hours (Fig. 4A, P<0.01). Similarly, Western blot analysis showed that HMGB1 treatment concomitantly diminished Mfn2 protein abundance in activated T cells (Fig. 4B and 4C).

To further explore the potential role of Mfn2 in HMGB1-induced apoptosis, we constructed a lentiviral vector expressing either Mfn2 (LV-Mfn2) or LV-pGC-FU (as a control 


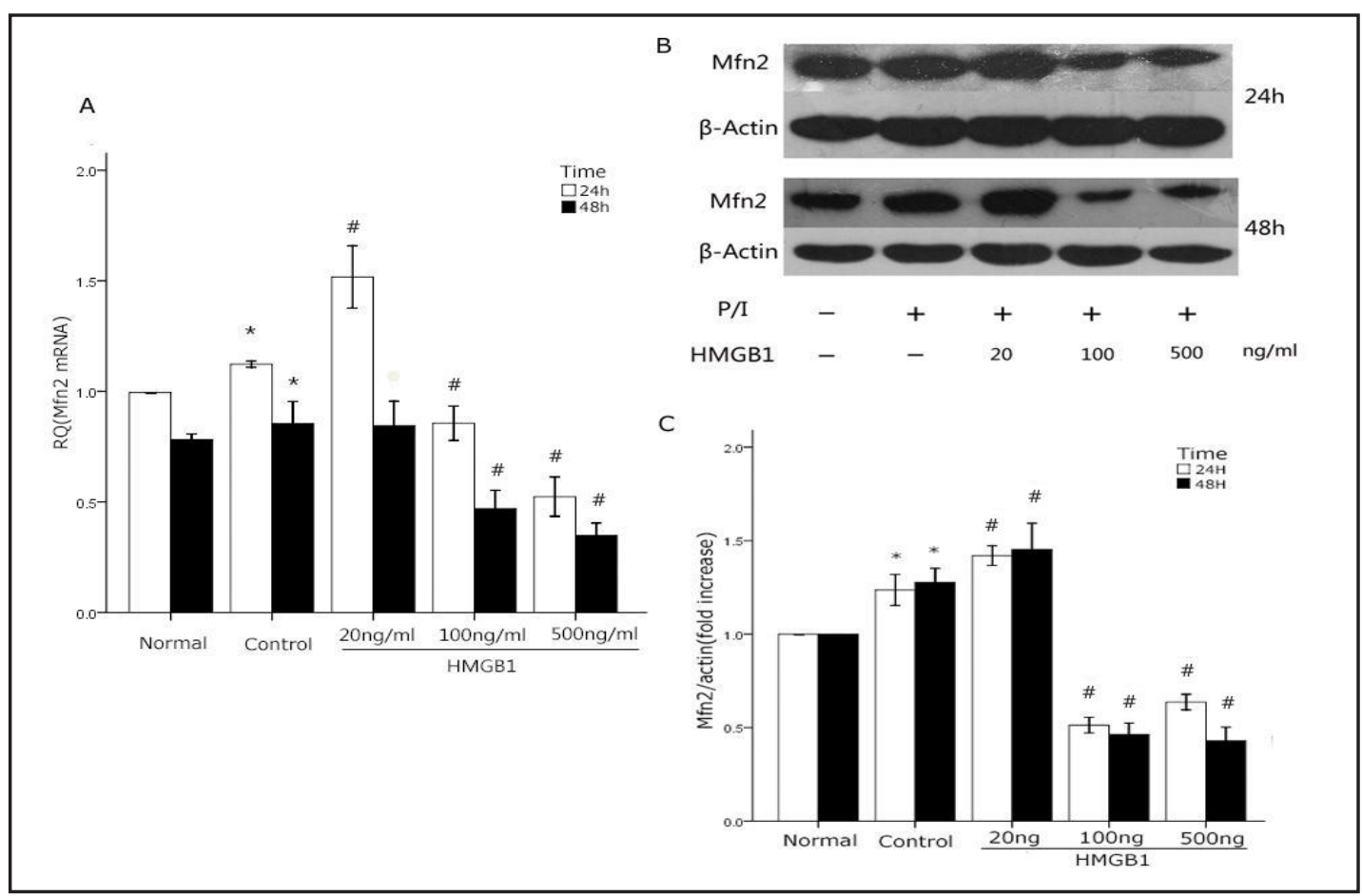

Fig. 4. Mfn-2 expression in response to P/I with or without HMGB1 stimulation. Jurkat T cells were incubated with P/I for 6 hours, then stimulated with HMGB1 $(20,100$, and $500 \mathrm{ng} / \mathrm{ml})$ or without HMGB1 (control). Cells without any stimulation served as baselines. (A) Mfn-2 mRNA expression by real-time PCR in Jurkat T cells in response to P/I with increasing concentration of HMGB1 or without HMGB1 (control) for 0,24 and 48 hours ( $n=4$ for each timepoint), respectively. (B and C) A representative Western blot with a Mfn2 antibody to assay Mfn2 expression in each group as indicated above. Results were shown as mean \pm SD. *Statistically significant difference when compared with the normal group $(\mathrm{P}<0.05)$; "Statistically significant difference when compared with controls $(\mathrm{P}<0.05)$.

Fig. 5. Mfn-2 expression in Jurkat $\mathrm{T}$ cells with LVMfn2 or LV-GFP transfected. A typical Western blot image and quantitative analysis for $\mathrm{Mfn}-2$ protein abundance in each group, $\beta$-actin was used as an internal control. Results of three independent experiments were shown as mean \pm SD. *Statistically significant difference when compared with the P/I group cells $(\mathrm{P}<0.01)$; \#Statistically significant difference when compared with unstimulated cells $(\mathrm{P}<0.01)$; \&Statistically significant when compared with the CORRESPONDING LV-pGC-FU cells $(\mathrm{P}<0.01)$.

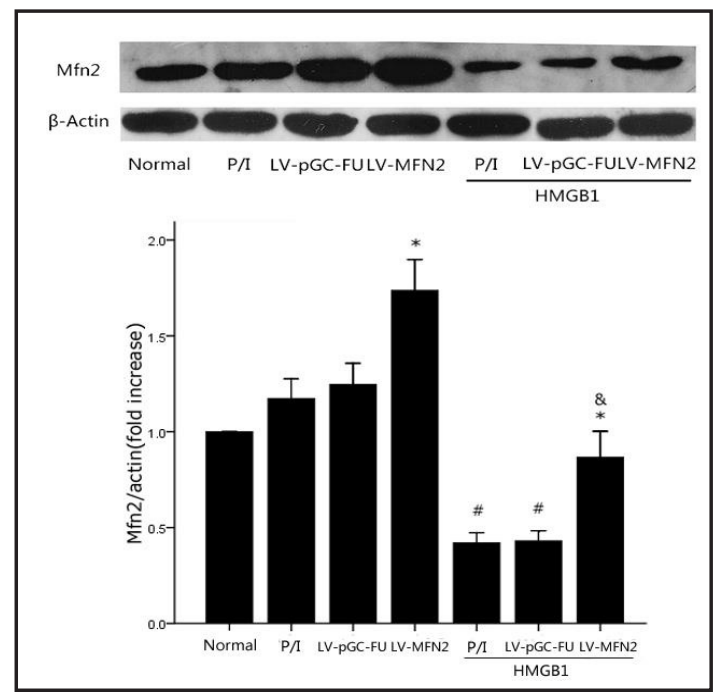

virus). The transfection efficiency for the LV-Mfn2 was estimated to be greater than $90 \%$ based upon transfection with a lentiviral vector that expresses the GFP reporter gene at MOI 50 (data not shown).

Fig. 5 illustrated LV-Mfn2 not only elevated Mfn2 protein abundance 48 hours after transfection, but also attenuated HMGB1-induced down-regulation of Mfn2 obviously. More 


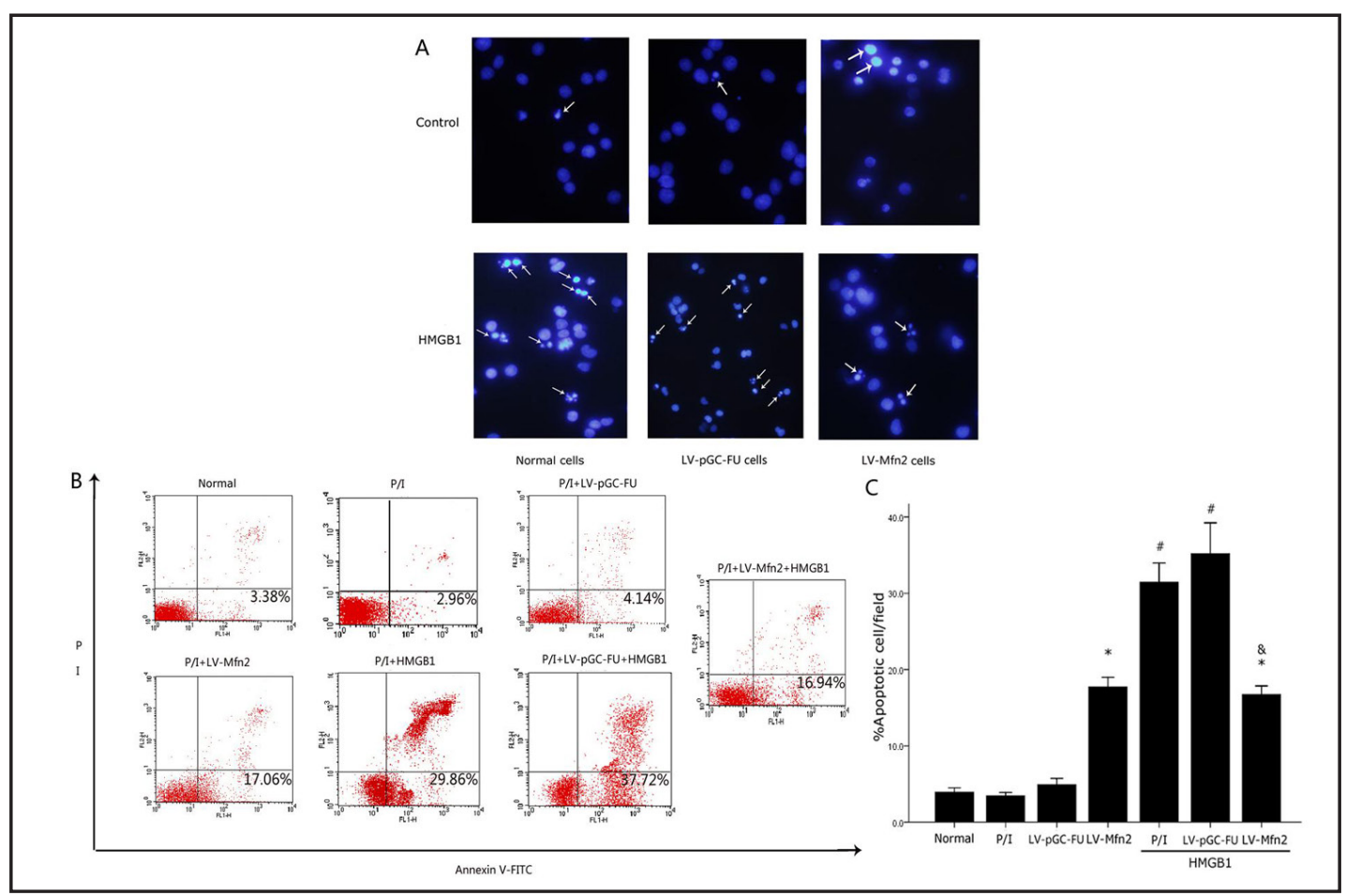

Fig. 6. Overexpression of Mfn2 by lentiviral infection attenuated the apoptosis effect of HMGB1 in Jurkat $\mathrm{T}$ cells. Before incubated with P/I, cells were uninfected (normal) or infected with 50 MOI of LV-pGC-FU or LV-Mfn2 for 48 hours, then stimulated with HMGB1 (500 ng/ml for 24 hours) or without HMGB1. (A) At the end of the HMGB1 incubation period, cells were stained with H-33342 and examined with a fluorescence microscope. Results were shown as one representative image of six different visual fields. The arrow points an apoptotic body in these images. Original magnification $\times 200$. (B and C) After treatment with HMGB1 for 24 hours, apoptosis of lentiviral infected or uninfected Jurkat T cells were stained with Annexin V-FITC and PI. Representative flow cytometry results from four fields of cells were shown in each experiment. Results of six independent experiments were shown as mean \pm SD. *Statistically significant difference when compared with the P/I group $(\mathrm{P}<0.01)$; \#Statistically significant difference when compared with unstimulated cells $(\mathrm{P}<0.01)$; \&Statistically significant when compared with the CORRESPONDING LV-pGC-FU cells $(\mathrm{P}<0.01)$.

importantly, overexpression Mfn2 could protect T cells against HMGB1-induced apoptosis. As expected, more viable cells were revealed with H33342 staining in LV-Mfn2 than LV-pGC-FU after HMGB1 stimulation (Fig. 6A). Notably, in absence of HMGB1, a part of T cells transfected with LV-Mfn2 became apoptotic $(\mathrm{P}<0.01$, Fig. 6). Taken together, the above results indicated that Mfn2 might be a key element in modulation of HMGB1-induced apoptosis of T cells.

Overexpression of Mfn2 attenuated the apoptotic effect of HMGB1 through influencing calcium concentration and mitochondrial membrane potential in T cells

It is well known that $\mathrm{Ca}^{2+}$ homeostasis controls a diversity of cellular processes including proliferation as well as apoptosis. Meanwhile, there are several clues indicating that Mfn2 plays a regulatory role in intracellular calcium signaling. The influence of Mfn2 on $\left[\mathrm{Ca}^{2+}\right]_{i}$ signaling with or without HMGB1 stimulation was investigated using a $\mathrm{Ca}^{2+}$ fluorescent probe, Fluo-3/AM. As shown in Fig. 7 and 8, T cell activation following $\mathrm{Ca}^{2+}$ influx, and treatment with $500 \mathrm{ng} / \mathrm{ml}$ HMGB1 resulted in significantly stronger fluorescent intensity in manifestation of $\left[\mathrm{Ca}^{2+}\right]_{\mathrm{i}}$ content compared to that in control $(\mathrm{P} / \mathrm{I})$ group $(\mathrm{P}<0.01)$. Furthermore, up-regulation of Mfn- 2 markedly prevented HMGB1-elicited $\left[\mathrm{Ca}^{2+}\right]_{\mathrm{i}}$ elevation while LV-pGC-FU had little effect on $\left[\mathrm{Ca}^{2+}\right]_{\mathrm{i}}$ content compared with controls. However, Mfn2 was also mediated an increase in $\left[\mathrm{Ca}^{2+}\right]_{\mathrm{i}}$ in a number of T cells $(\mathrm{P}<0.01)$. 
Fig. 7. Mfn2 keeps $\left[\mathrm{Ca}^{2+}\right]_{\mathrm{i}}$ homeostasis in Jurkat $\mathrm{T}$ cell. $\left[\mathrm{Ca}^{2+}\right]_{\mathrm{i}}$ was monitored by using a fluorescence-activated cell sorter (FACS) with fluorescent probe, Fluo-3/AM in during 0-13h. PMA (50ng/ml)/ionomycin $(1 \mu \mathrm{M})[\mathrm{P} / \mathrm{I}]$ and HMGB1(500ng/ml) were added to cell culture medium at time point of $1 \mathrm{~h}$ and $7 \mathrm{~h}$, respectively. Data represent mean \pm SD from 2 independent experiments performed in triplicate.

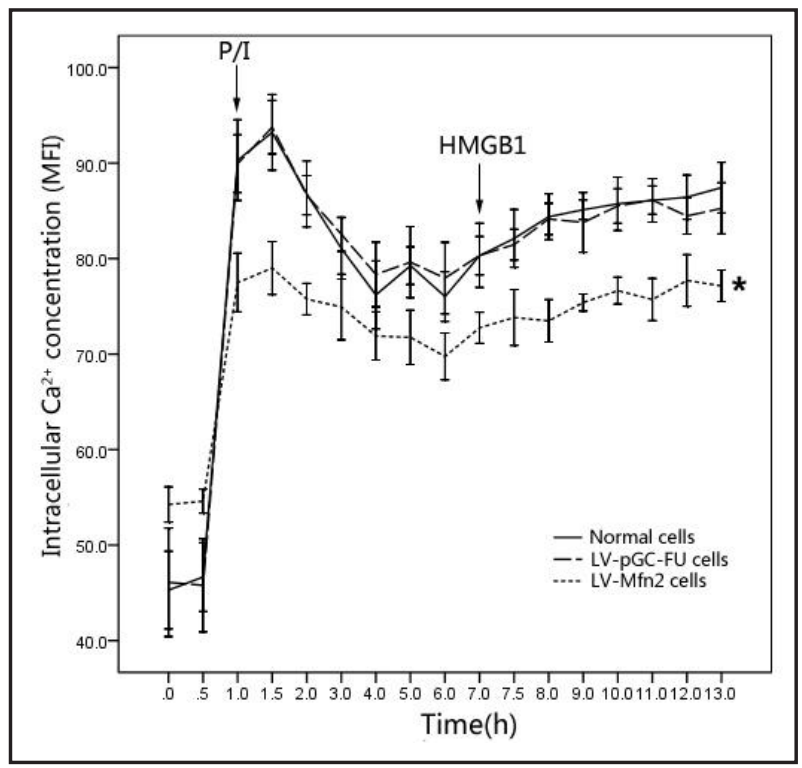

Next, to clarify whether variations in cytoplasmic calcium were associated with mitochondrial membrane potential of Jurkat T cells, another fluorescent probe JC-1 was used. This stabilization effect was also confirmed by mitochondrial membrane potential assay (Fig. 9). Additionally, overexpression of Mfn2 preferentially inhibited the activity of caspase-9 (Fig. 2). This result further substantiates our conclusion that HMGB1 promotes apoptosis of T cells via the mitochondrial apoptotic signaling pathway.

\section{Discussion}

In 1999, Wang et al. described HMGB1 as a late mediator in lethal endotoxemia by exacerbating systemic inflammatory response and organ dysfunction [17]. To date, studies by our group and others indicate that HMGB1 also has immune-modulatory effects besides its proinflammatory activity. Intracellular HMGB1 was discovered to serve as a sentinel for DNA and RNA activation in the innate and subsequent adaptive immune response [18]. On the other hand, extracellular HMGB1 is potent in initiating immune responses by inducing migration and activation of antigen presenting cell $[10,11]$, and in turn, mediating Th1 polarization [19]. With the increased concentration and prolonged stimulation time, HMGB1 inhibits T cell proliferation activity, with shifting of Th1 to Th2, and enhancement of suppressive capacity of $\mathrm{CD} 4{ }^{+} \mathrm{CD} 25^{+}$Tregs in vitro $[13,20]$. Corroborating above findings, in the current study we have shown that a high dose of HMGB1 notably induced apoptosis of Jurkat $\mathrm{T}$ cells (a human $\mathrm{T}$ cell line), but not in a low concentration.

It is noteworthy that the release of HMGB1 into the extracellular milieu begins 8-12 hours after ligation of Toll-like receptors (TLRs), and its concentration continues to increase for 18-36 hours [17]. In clinical settings, most patients with sepsis will survive the initial hyper-inflammatory phase followed by the development of a sustained immunosuppressive state, and at that time T cells undergo apoptosis [4]. Thus, the kinetics of HMGB1 secretion coincide with the shift toward an immunosuppressive state in sepsis, and HMGB1 may be responsible for a persisting immune dysfunction in patients. Therefore, it seems that attenuating systemic HMGB1 accumulation is beneficial with lowering mortality in animal studies [21].

Autopsy studies in patients who had died of severe sepsis revealed a profound, progressive apoptosis of $\mathrm{CD}^{+} \mathrm{T}$ cells [3]. Similar phenomenon is also found in septic animals. Apoptosis of T cells is recognized as a critical event in immunosuppressive state in sepsis. Nevertheless, it has been shown that the magnitude of T-cell apoptosis has been positively correlated with 


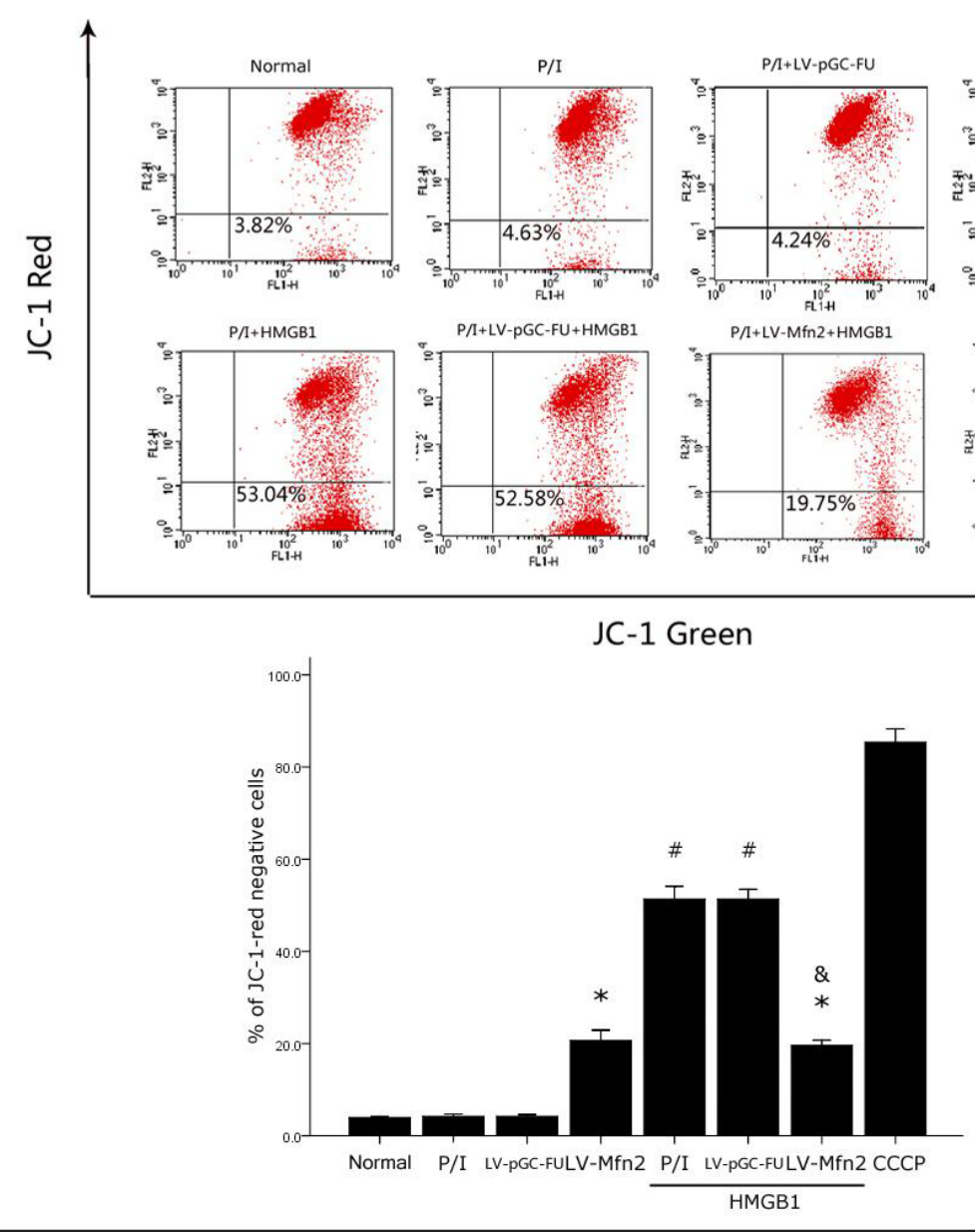

Fig. 8. Up-regulation of Mfn-2 protected Jurkat T cells against HMGB1 induced $\left[\mathrm{Ca}^{2+}\right]_{\mathrm{i}}$ disturbance. Significantly stronger $\left[\mathrm{Ca}^{2+}\right]_{\mathrm{i}}$ fluorescent visualizations were noticed post treatment of $\mathrm{P} / \mathrm{I}$-activated Jurkat $\mathrm{T}$ cells with $500 \mathrm{ng} / \mathrm{ml} \mathrm{HMGB} 1$ for 24 hours, using a fluorescence-activated cell sorter (FACS) with fluorescent probe, Fluo-3/AM. Results of four individual experiments were shown as mean \pm SD. *Statistically significant difference when compared with the $\mathrm{P} / \mathrm{I}$ cells $(\mathrm{P}<0.01)$; \#Statistically significant difference when compared with unstimulated cells $(\mathrm{P}<0.01)$; \&Statistically significant difference when compared with CORRESPONDING LV-pGC-FU cells $(\mathrm{P}<0.01)$.

sepsis severity [22], and with prevention of T-cell apoptosis improved the host response to sepsis $[23,24]$. To elucidate the precise pathway of inducing apoptosis of T cells and apoptotic mechanism in sepsis is an urgent and vital task. Our data demonstrated that HMGB1 was a key factor to elicit T-cell apoptosis. Meanwhile, it was found that treatment with HMGB1 could decrease the level of mitochondrial anti-apoptotic protein Bcl-2, while increase Bax mitochondrial accumulation, and activate caspases in T cells. Although both caspase- 8 and caspase- 9 are activated in this process, the degree of caspase- 8 activation is lower than that of caspase-9. Furthermore, the interaction between the mitochondrial pathway and the death receptor-mediated pathway might be feasible that activated caspase- 9 could result in activated caspase-8 or vice versa [25]. Therefore, it is believed that apoptotic effect of HMGB1 on T cells is mainly mediated by the mitochondrial apoptotic pathway. Nevertheless, nuclear shrunk of T cell after HMGB1 treatment was observed by fluorescence microscope in a time- and concentration-dependent manner. As a nuclear-associated protein, HMGB1 released from apoptotic cells or necrotic cells may exacerbate $\mathrm{T}$ cell apoptosis based on more necrosis or late apoptosis emerged in 48h with 500ng/ml HMGB1. 


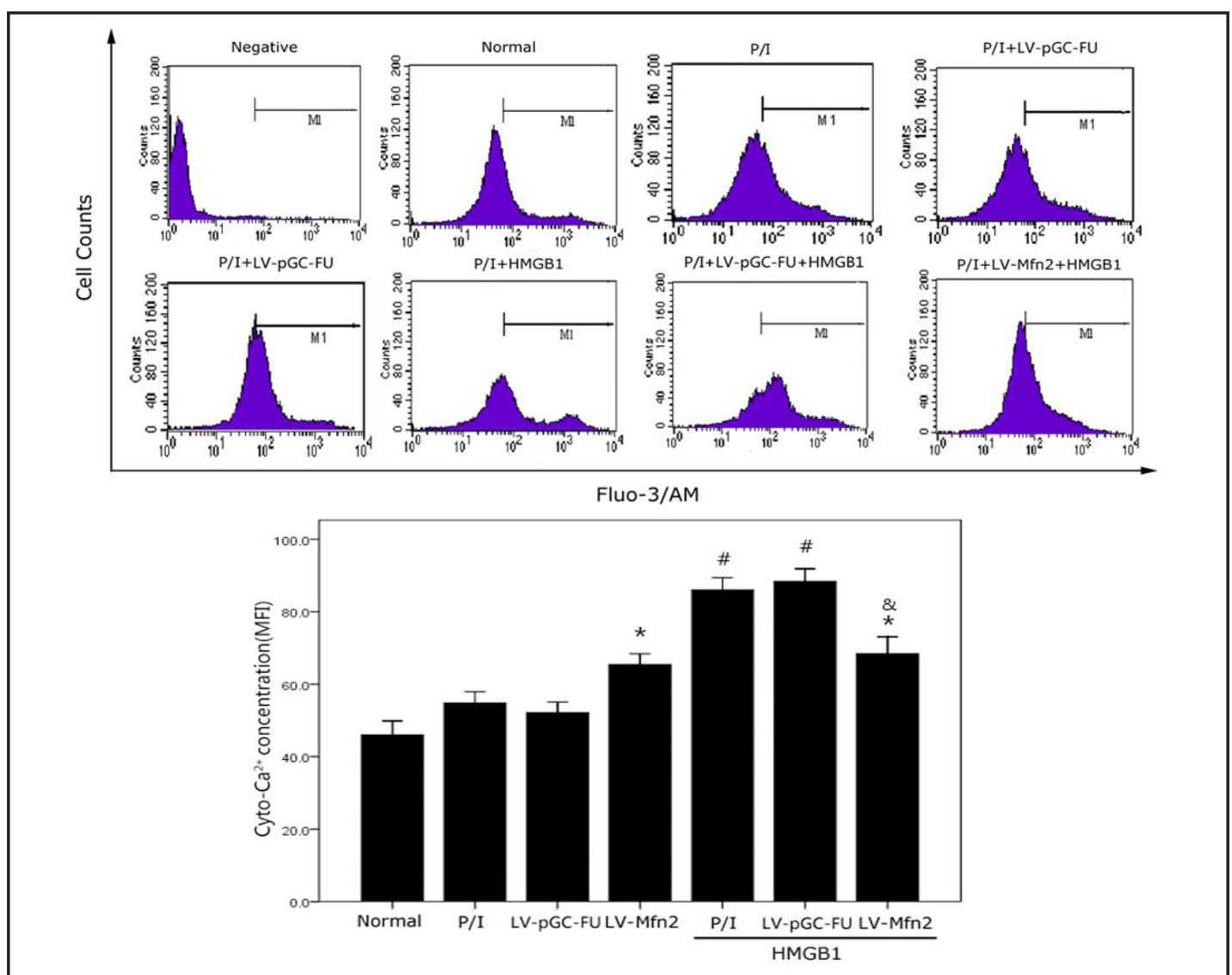

Fig. 9. Changes in mitochondrial membrane potential in uninfected cells and infected with $50 \mathrm{MOI}$ of LVpGC-FU or LV-Mfn2 in presence or absence of HMGB1. After treatment with HMGB1 (500 ng/ml, 24 hours) as indicated, cells were labeled with the JC-1 probe for analysis by flowcytometry. The subpopulation of cells displaying normal (JC-1 green and red fluorescence) and reduced (positive JC- 1 green and negative JC- 1 red fluorescence) levels of mitochondrial membrane potential were indicated. CCCP controls were used to confirm that the JC-1 response was sensitive to changes in membrane potential. Each value was expressed as the mean \pm SD of four determinations. *Statistically significant difference when compared with the P/I cells $(\mathrm{P}<0.01)$; \#Statistically significant difference when compared with unstimulated cells $(\mathrm{P}<0.01)$; \&Statistically significant difference when compared with CORRESPONDING LV-pGC-FU cells $(\mathrm{P}<0.01)$.

It is interesting to note that, as a mitochondrial fusion protein, Mfn2 has low GTPase activity and efficiency in mitochondrial tethering reaction [26]. There is growing evidence supporting that additional role for Mfn2 other than the regulation of the mitochondrial morphology. Mfn2 also locates in ER and it is enriched at the contact site between ER and mitochondria. Deletion of Mfn2 impairs the ER-mitochondria juxtaposition and $\mathrm{Ca}^{2+}$ signals between them [15]. More recently, Mfn2 was reported to play a role in regulation of CRAC protein trafficking across the ER. Cells lacking Mfn2 seem to be more sensitive to mitochondrial depolarization, suggesting that there is a significant correlation between Mfn2 and $\mathrm{Ca}^{2+}$ influx[16]. Sustaining $\left[\mathrm{Ca}^{2+}\right]_{\mathrm{i}}$ elevation leads to collapse of mitochondrial membrane potential, triggering intrinsic apoptotic pathway [27]. In this context, we have utilized fluorescent probes to detect $\left[\mathrm{Ca}^{2+}\right]_{i}$ and mitochondrial membrane potential. Not surprisingly, HMGB1 induced $\mathrm{Ca}^{2+}$ overload in T cells and destroyed mitochondrial membrane potential intensively. When T cells were incubated with HMGB1, the expression of Mfn2 was decreased gradually in a dose- and time-dependent manner. In contrast, with preservation 
of Mfn2 expression was shown to prevent $\mathrm{Ca}^{2+}$ disequilibrium with resistance of HMGB1induced apoptosis of T cells. Therefore, down-regulation of Mfn2 expression of T cells by HMGB1 maybe the key process responsible for apoptosis. Besides, these observations are in agreement with the fact that Mfn2 is a protective factor in host suffering from cold stress, DNA damage and cellular injury due to reactive oxygen species [28, 29]. Neuspiel et al. have reported that Mfn2 activity could affect mitochondrial recruitment of Bax during cell death, and activation of Mfn2 protected the mitochondria from permeability transition [30]. However, in other scenario, Mfn2 acts as a proapoptotic molecule as well. For instance, overexpression of Mfn2 in vascular smooth muscle cells and cardiomyocytes causes inhibition of Akt signaling resulting in activation of the mitochondrial apoptotic pathway [31, 32]. It is worth notice that without GTPase activity Mfn2 still retains its proapoptotic effect, and it indicates that Mfn2-induced apoptosis is independent of mitochondrial fusion [32]. Therefore, the mechanisms underlying involvement of Mfn2 in programmed cell death are as follows: 1) promoting mitochondrial fusion; 2) reducing Bax activation and cytochrome $\mathrm{C}$ release by co-localization with activated Bax; 3 ) interfering with the Ras-PI3K-Akt pathway; 4) affecting intracellular $\mathrm{Ca}^{2+}$ signalling. The first two pathways are cell protective, whereas the third may bring about cell death. The exact effect of Mfn2 in apoptosis may depend on cell type and stimuli in determining which mechanism is predominant. Apart from that, the relationship between $\mathrm{Mfn} 2$ and $\mathrm{Ca}^{2+}$ signaling still requires further clarification.

Recently, Ngoh et al. demonstrated that pharmacologic induction of ER stress could upregulate Mfn2 expression, and ablation of the Mfn2 gene had also been shown to sensitize cells to ER stress-induced cell death [33]. Elevating Mfn2 expression enhanced mitochondriaER connection, thus probably affecting $\mathrm{Ca}^{2+}$ transfer and amplification of apoptotic signals $[15,34]$. On the other hand, cellular deficiency of Mfn2 would be devoid of a homeostatic mechanism to counteract the deleterious effects. We concurred in our previous work that reduction of Mfn2 expression was associated with a declination in NF-AT activity of T cells by disturbing $\mathrm{Ca}^{2+}$ signals [13]. However, in the current study, we have shown that up-regulation of Mfn2 impaired $\mathrm{Ca}^{2+}$ homeostasis of T cells, and a part of cells underwent apoptosis eventually. Thus, it is conceivable that Mfn2 may play a dual role in regulation of intracellular $\mathrm{Ca}^{2+}$. Either arise or a fall of Mfn2 expression influences $\mathrm{Ca}^{2+}$ signals, therefore maintaining a certain amount of Mfn2 will be profitable for organism to guard against a variety of different stresses and lesions.

As a ubiquitous second messenger, the pivotal role of $\mathrm{Ca}^{2+}$ signaling in cellular function of $\mathrm{T}$ lymphocytes including differentiation, proliferation, apoptosis, and effector function is well characterized. To our knowledge, the rapid $\mathrm{Ca}^{2+}$ influx is absolutely crucial for the activation of T cells, while continuous high $\mathrm{Ca}^{2+}$ signals and subsequent high mitochondrial $\mathrm{Ca}^{2+}$ load are correlated with apoptosis [27, 34]. Whether it is a transient elevation, a repetitive oscillation, or a sustained elevation, SOCE via CRAC channels is the major pathway for $\left[\mathrm{Ca}^{2+}\right]$ i elevation in T cells. More recently, the morphology change of ER and mitochondria induced by the loss of $m f n 2$ has been observed at the ultrastructural level. Contrary to de Brito OM et al. study [15], the results showed the juxtaposition of ER and mitochondria is increased by loss of $\mathrm{mfn} 2$, suggesting that $\mathrm{Mfn} 2$ is not essential for this process [35]. In view of the effect of Mfn2 on juxtaposition of ER and Mitochondria is too ambiguous to determine. To get further insight into Mfn2 and intracellular $\mathrm{Ca}^{2+}$, the relationship between $\mathrm{Mfn} 2$ and CRAC channel are needed to explore immediately.

In summary, we have identified the apoptotic effect of HMGB1 on T cells. Up-regulation of Mfn2 in T cells provides a resistence to HMGB1-induce apoptosis by maintain $\mathrm{Ca}^{2+}$ homeostasis. As intracellular $\mathrm{Ca}^{2+}$ is vital to T cells, Mfn2 may also be a essential regulator of the $\mathrm{T}$ cell function. Because dysfunction of $\mathrm{T}$ cells appears to be a crucial cellular process involved in the development of immunologic diseases/autoimmune diseases, these findings might disclose new drug targets and therapeutic strategies for sepsis, autoimmunity as well as immunodeficency diseases. 
Wu et al.: Mfn-2 in HMGB1-Mediated Apoptosis of T Cells

\section{Acknowledgements}

This work was supported, in part, by grants from the National Natural Science Foundation (No. 81071593, 81130035, 81071545, 81121004), the Key Construction Academic Subject (Medical Innovation) of Zhejiang Province (No. 11-CX26), the Key Disciplines in Colleges and Universities of Zhejiang Province, the National Basic Research Program of China (No. 2012CB518102) and Zhejiang provincial natural science foundation of China ( LY13H150006).

\section{References}

1 Hiramatsu M, Hotchkiss RS, Karl IE, Buchman TG: Cecal ligation and puncture (CLP) induces apoptosis in thymus, spleen, lung, and gut by an endotoxin and TNF-independent pathway. Shock 1997;7:247-253.

- Hotchkiss RS, Swanson PE, Freeman BD, Tinsley KW, Cobb JP, Matuschak GM, Buchman TG, Karl IE: Apoptotic cell death in patients with sepsis, shock, and multiple organ dysfunction. Crit Care Med 1999;27:1230-1251.

-3 Hotchkiss RS, Tinsley KW, Swanson PE, Schmieg RE Jr, Hui JJ, Chang KC, Osborne DF, Freeman BD, Cobb JP, Buchman TG, Karl IE: Sepsis-induced apoptosis causes progressive profound depletion of B and CD4+ T lymphocytes in humans. J Immunol 2001;166:6952-6963.

4 Hotchkiss RS, Karl IE: The pathophysiology and treatment of sepsis. N Engl J Med 2003;348:138-150.

5 Hotchkiss RS, Nicholson DW: Apoptosis and caspases regulate death and inflammation in sepsis. Nature reviews. Immunology 2006;6:813-822.

6 Hotchkiss RS, Chang KC, Grayson MH, Tinsley KW, Dunne BS, Davis CG, Osborne DF, Karl IE: Adoptive transfer of apoptotic splenocytes worsens survival, whereas adoptive transfer of necrotic splenocytes improves survival in sepsis. Proc Natl Acad Sci U S A 2003;100:6724-6729.

7 Kasten KR, Tschop J, Adediran SG, Hildeman DA, Caldwell CC: T cells are potent early mediators of the host response to sepsis. Shock 2010;34:327-336.

8 Wang H, Yang H, Tracey KJ: Extracellular role of HMGB1 in inflammation and sepsis. J Intern Med 2004;255:320-331.

-9 Karlsson S, Pettilä V, Tenhunen J, Laru-Sompa R, Hynninen M, Ruokonen E: HMGB1 as a predictor of organ dysfunction and outcome in patients with severe sepsis. Intensive Care Med 2008;34:1046-1053.

10 Yang D, Chen Q, Yang H, Tracey KJ, Bustin M, Oppenheim JJ: High mobility group box-1 protein induces the migration and activation of human dendritic cells and acts as an alarmin. J Leukoc Biol 2007;81:59-66.

-11 Rouhiainen A, Kuja-Panula J, Wilkman E, Pakkanen J, Stenfors J, Tuominen RK, Lepäntalo M, Carpén 0, Parkkinen J, Rauvala H: Regulation of monocyte migration by amphoterin (HMGB1). Blood 2004;104:11741182.

12 Zhu XM, Yao YM, Liang HP, Liu F, Dong N, Yu Y, Sheng ZY: Effect of high mobility group box-1 protein on apoptosis of peritoneal macrophages. Arch Biochem Biophys 2009;492:54-61.

-13 Zhao GJ, Yao YM, Lu ZQ, Hong GL, Zhu XM, Wu Y, Wang DW, Dong N, Yu Y, Sheng ZY: Up-regulation of mitofusin-2 protects CD4+ T cells from HMGB1-mediated immune dysfunction partly through $\mathrm{Ca}^{2+}$-NFAT signaling pathway. Cytokine 2012;59:79-85.

14 Oh-hora M: Calcium signaling in the development and function of T-lineage cells. Immunol Rev 2009;231:210-224.

-15 de Brito OM, Scorrano L: Mitofusin 2 tethers endoplasmic reticulum to mitochondria. Nature 2008;456:605-610.

-16 Singaravelu K, Nelson C, Bakowski D, de Brito OM, Ng SW, Di Capite J, Powell T, Scorrano L, Parekh $\mathrm{AB}$ : Mitofusin 2 regulates STIM1 migration from the $\mathrm{Ca}^{2+}$ store to the plasma membrane in cells with depolarized mitochondria. J Biol Chem 2011;286:12189-12201.

17 Wang H, Bloom O, Zhang M, Vishnubhakat JM, Ombrellino M, Che J, Frazier A, Yang H, Ivanova S, Borovikova L, Manogue KR, Faist E, Abraham E, Andersson J, Andersson U, Molina PE, Abumrad NN, Sama A, Tracey KJ: HMG-1 as a late mediator of endotoxin lethality in mice. Science 1999;285:248-251. 
Wu et al.: Mfn-2 in HMGB1-Mediated Apoptosis of T Cells

18 Yanai H, Ban T, Wang Z, Choi MK, Kawamura T, Negishi H, Nakasato M, Lu Y, Hangai S, Koshiba R, Savitsky D, Ronfani L, Akira S, Bianchi ME, Honda K, Tamura T, Kodama T, Taniguchi T: HMGB proteins function as universal sentinels for nucleic-acid-mediated innate immune responses. Nature 2099;462:99-103.

19 Zhang LT, Yao YM, Yao FH, Huang LF, Dong N, Yu Y, Sheng ZY: Association between high-mobility group box-1 protein release and immune function of dendritic cells in thermal injury. J Interferon Cytokine Res 2010;30:487-495.

20 Wild CA, Bergmann C, Fritz G, Schuler P, Hoffmann TK, Lotfi R, Westendorf A, Brandau S, Lang S: HMGB1 conveys immunosuppressive characteristics on regulatory and conventional T cells. Int Immunol 2012;24:485-494.

21 Wang H, Zhu S, Zhou R, Li W, Sama AE: Therapeutic potential of HMGB1-targeting agents in sepsis. Expert Rev Mol Med 2008;10:e32.

22 Chang KC, Unsinger J, Davis CG, Schwulst SJ, Muenzer JT, Strasser A, Hotchkiss RS: Multiple triggers of cell death in sepsis: death receptor and mitochondrial-mediated apoptosis. FASEB J 2007;21:708-719.

23 Hotchkiss RS, Coopersmith CM, Karl IE: Prevention of lymphocyte apoptosis--a potential treatment of sepsis? Clin Infect Dis 2005;41:S465-469.

24 Unsinger J, McGlynn M, Kasten KR, Hoekzema AS, Watanabe E, Muenzer JT, McDonough JS, Tschoep J, Ferguson TA, McDunn JE, Morre M, Hildeman DA, Caldwell CC, Hotchkiss RS: IL-7 promotes T cell viability, trafficking, and functionality and improves survival in sepsis. J Immunol 2010;184:768-3779. Hotchkiss RS, Strasser A, McDunn JE, Swanson PE: Cell death. N Engl J Med 2009;361:1570-1583.

26 IIshihara N, Eura Y, Mihara K: Mitofusin 1 and 2 play distinct roles in mitochondrial fusion reactions via GTPase activity. J Cell Sci 2004;117:6535-6546.

27 Giorgi C, Romagnoli A, Pinton P, Rizzuto R: $\mathrm{Ca}^{2+}$ signaling, mitochondria and cell death. Curr Mol Med 2008;8:119-130.

-28 Jahani-Asl A, Cheung EC, Neuspiel M, MacLaurin JG, Fortin A, Park DS, McBride HM, Slack RS: Mitofusin 2 protects cerebellar granule neurons against injury-induced cell death. J Biol Chem 2007;282:23788-23798.

-29 Zhang W, Chen Y, Yang Q, Che H, Chen X, Yao T, Zhao F, Liu M, Ke T, Chen J, Luo W: Mitofusin-2 protects against cold stress-induced cell injury in HEK293 cells. Biochem Biophy Res Commun 2010;397:270-276.

30 Neuspiel M, Zunino R, Gangaraju S, Rippstein P, McBride H: Activated mitofusin 2 signals mitochondrial fusion, interferes with Bax activation, and reduces susceptibility to radical induced depolarization. J Biol Chem 2005;280:25060-25070.

- 31 Chen KH, Guo X, Ma D, Guo Y, Li Q, Yang D, Li P, Qiu X, Wen S, Xiao RP, Tang J: Dysregulation of HSG triggers vascular proliferative disorders. Nat Cell Biol 2004;6:872-883.

32 Guo X, Chen KH, Guo Y, Liao H, Tang J, Xiao RP: Mitofusin 2 triggers vascular smooth muscle cell apoptosis via mitochondrial death pathway. Cir Res 2007;101:1113-1122.

-33 Ngoh GA, Papanicolaou KN, Walsh K: Loss of mitofusin 2 promotes endoplasmic reticulum stress. J Biol Chem 2012;287:20321-20332.

-34 Parekh A: Calcium signalling: mitofusins promote interorganellar crosstalk. Curr Biol 2009;19:R200-203.

- 35 Cosson P, Marchetti A, Ravazzola M, Orci L: Mitofusin-2 independent juxtaposition of endoplasmic reticulum and mitochondria: an ultrastructural study. PLoS One 2012;7:e46293 